\title{
Kontribusi Tarekat Naqsabandiyah Dalam Membangun Pendidikan Akhlak Mulia
}

\author{
Hamzah*, Nasrul \\ Universitas Islam Riau, Indonesia*, Universitas Islam Riau, Indonesia \\ *Jl. Kaharuddin Nst No.113, Simpang Tiga, Kec. Bukit Raya, Kota Pekanbaru, Riau 28284 \\ *Email: hamzah@fis.uir.ac.id
}

\begin{abstract}
The study on Naqsabandiyah Order (Tariqa) has been widely carried out, but the findings on its contribution to the Ukui Dua Pelalawan community have not been found yet. This study aims to investigate the contribution of Naqsabandiyah Order in Building Education for the Community in Ukui Dua Village, Pelalawan Regency, Riau Province. The type of this study is qualitative with three research informants. The data collection technique used is interviews and they are analyzed with the steps of data reduction, data display, and drawing conclusions. The results of this study show that there are 20 contributions of Naqsabandiyah Order in building Moral Education for the Community, namely: Presenting a sense of Faith and Taqwa to Allah SWT; Taking care of ourselves; Religious lectures and Tabligh Akbar; Islamic studies; Tawakkal and Gratitude; Penance and Dhikr; Reciting Surah Yaasin; Tausiyah and fasting; Tawheed; Ridha; Celebrating the Birthday of Prophet Muhammad P.B.U.H. and Isra' Mi'raj; Hadith and As-sunnah; Salawat; Expressing greetings; Tolerating; A sense of caring; doing pilgrimage; Fulfiling the invitation; Loving animals and taking care of plants; and Being as a Caliph. The benefits of this study for local governments and especially for tariqa teachers are as a reference for the development of moral education learning and as an enrichment for Islamic culture.
\end{abstract}

Keywords: Tarekat Naqsabandiyah, Education, Character

Abstrak: Penelitian tentang Tarekat Naqsabandiyah telah banyak dilakukan, namun melihat kontribusinya di masyarakat Ukui Dua Pelalawan belum ditemukan. Penelitian ini bertujuan untuk mengetahui Kontribusi Tarekat Naqsabandiyah dalam Membangun Pendidikan Masyarakat Desa Ukui Dua Kabupaten Pelalawan Riau. Jenis penelitian ini kualitatif dengan tiga orang informan penelitian. Data dikumpulkan dengan wawancara dan dianalisis, penyajian data, reduksi data, penarikan kesimpulan. Hasil penelitian ini menunjukan terdapat 20 kontribusi Tarekat Naqsabandiyah dalam membangun Pendidikan Akhlak Masyarakat yaitu; Menghadirkan rasa Iman dan Taqwa kepada Allah Swt; Memelihara dirinya; Ceramah agama dan Tabligh Akbar; Kajian-kajian keIslaman; Tawakkal dan Bersyukur; Tobat dan Dzikir; Yasinan; Tausiyah dan puasa; Tauhid; Ridha; Maulid Nabi Muhammad Saw. dan isra' mi'raj; Hadist dan As-sunnah; Bershalawat; Mengucapkan salam; Bertoleransi; Rasa kepedulian; Berziarah; Memenuhi undangan; Mencintai hewan dan Memelihara tumbuhan; Khalifah. Kegunaan penelitian bagi pemerintah setempat khususnya para guru tarekat sebagai bahan acuan terhadap pengembangan pembelajaran pendidikan akhlak dan sebagai memperkaya kebudayaan Islam.

Kata Kunci: Tarekat Naqsabandiyah, Pendidikan, Akhlak

Jurnal Pendidikan Agama Islam Al-Thariqah Vol. 5, No. 2, Juli - Desember 2020

Received: 02 September 2020; Accepted 17 December 2020; Published 21 December 2020

*Corresponding Author: hamzah@fis.uir.ac.id 


\section{PENDAHULUAN}

Pendidikan suatu hal yang sangat penting dalam mengembangkan seluruh aspek kepribadian manusia. Dalam Islam kepribadian merupakan salah satu faktor yang sangat penting, bahwa tujuan pendidikan Islam itu tertuju pada pembentukan kepribadian. Di zaman sekarang ini, banyak orang yang mengetahui agama tetapi tidak merealisasikan dalam kehidupanya. Pendidikan akhlak tidak akan pernah terlepas dari ajaran Islam, dimana pendidikan akhlak suatu proses mendekatkan manusia kepada tingkat kesempurnaan dan mengembangkan kemampuanya, salah satu contohnya dalam hal ini adalah tasawuf (Mubarok \& Giyoto, 2020).

Ahklak dalam kehidupan manusia menempati suatu hal kedudukan yang penting, sebagai individu maupun masyarakat dan bangsa, sebab jatuh bangunya suatu masyarakat itu tergantung kepada akhlaknya. Apabila masyarakat itu akhlaknya baik, maka sejahteralah lahir dan batinya, kemudian apabila akhlak di masyarakat itu rusak maka rusaklah lahir dan batinnya. Menurut Al-Ghazali dalam Abuddin Nata akhlak ialah seluruh aspek kehidupan manusia baik secara individu (perseorangan) maupun kelompok (Agus, 2018).

Akhlak kepada sesama manusia merupakan sikap antara manusia dengan orang lain. Dalam kehidupan ini, selain manusia berinteraksi kepada Tuhan, manusia yang lain, bahkan manusia dengan alam. Pada saat ini masyarakat telah mampu menguasai teknologi yang sangat canggih dan modern pada masa kini, disamping membawa dampak positif teknologi yang cangggih juga membawa dampak negatif salah satunya dapat merusak akhlak masyarakat. Ada sebagian kalangan pendapat saat ini bangsa Indonesia mengalami kemerosotan tingkah laku yang berada pada taraf yang memprihatikan. Agama Islam menempatkan akhlak sebagai yang wajib untuk dilaksanakan oleh setiap manusia baik itu kaum laki-laki dan perempuan (Nasution, 2019). Bahkan dalam hadist Nabi SAW pernah dikatakan "tuntutlah ilmu dari buayan sampai ke liang lahat". Hal ini mengisyaratakan bahwa menuntuk Ilmu itu mulai sejak kandungan sampai manusia itu meninggal dunia. Sedangkan Pendidikan di Indonesia terbagi beberapa jalur yaitu formal, nonformal, dan informal. Pendidikan nonformal merupakan jalur pendidikan di luar pendidikan formal yang dapat dilakukan secara terstruktur dan berjenjang, seperti lembaga kursus, kelompok belajar, bahkan Lembaga tarekat. Untuk melihat pendidikan yang dilakukan dengan tarekat atau tasawuf, harus memiliki kembali apa tujuan dari tujuan akhir Pendidikan akhlak itu sendiri. Karena ajaran tarekat juga merupakan ajaran Islam yang tidak bisa terpisakan dari pembentukan akhlak manusia. Jika tujuan akhir dari pendidikan Islam adalah terwujudnya manusia sebagai hamba Allah, maka pendidikan haruslah dapat menjadikan seluruh manusia mau menghambakan diri kepada Allah SWT (Abdullah, 2018).

Menurut Anwar dalam tambak menyatakan bahwa psikososial Islam memiliki kontribusi yang tinggi terhadap pengembangan kualitas diri manusia dalam setiap profesi yang dilakukan (Tambak, Sukenti : 2020). Salah satu kentribusi Islam yaitu Tarekat Naqsabandiyah memiliki peran dalam menumbuh kembangkankan akhlak masyarakat desa Ukui Dua sehingga masyarakat memiliki jiwa yang berakhlak mulia, dan mampu menjadi teladan serta menciptakan kasih sayang antara sesama makhluk, di masyarakat guru (mursyid), wakil guru (badal/khalifah) sudah mencontohkan melalui sikap, yang dilakukan keseharian dengan tingkah laku, dan perbuatan yang telah 
mencerminkan sosok seorang guru (mursyid), dan wakil guru (badal/khalifah) dalam ajaran tarekat. Dari sinilah dapat diketahui peran tarekat Naqsabandiyah dalam membangun pendidikan Akhlak masyarakat desa Ukui dua mendapatkan perubahan yang lebih baik, ketenangan jiwa, maupun mendidik ahklak serta ketaatan dalam beribadah kepada Allah dan berbuat baik sesama makhluk melaui dengan hidup sederhana, Zuhud.

\section{KONSEP TEORI}

Asal kata tarekat dalam bahasa Arab ialah "thariqah" yang berarti jalan, keadaan, aliran, atau garis pada sesuatu. Dapat pula digambarkan sebagai jalan yang berpangkal dari syari at sebab jalan utama disebut syar', sedangkan anak jalan disebut thariq (Anwar, 2014). Pengertian Tarekat Naqsyabandiyah terdiri dari tiga kata "Tharikat, Naqsya, bandy". Tharekat artinya jalan (suluk) yakni perjalanan jiwa (rohani) kepada Allah, Naqsya artinya ukuir atau garis dan bandi artinya berkekalan atau berkepanjangan. Jadi Tarekat Naqsyabandiyah maka artinya perjalanan hati berkekalan atau berkepanjangan mengingat Allah (Wahyuningsih, 2014). Dalam Sabilus Salikin Tarekat ini disebut dengan Naqsabandiyah, karena dinisbatkan pada Naqsya Bandi yang artinya sambungan pahatan. An-Naqsy adalah bentuk cap (stempel) yang dicapkan pada malam (sejenis lilin) dan sebagainya. Rabithahnya (sambungan) adalah tetapnya Naqsyabandi yang tidak lebur, maksudnya adalah Sayyid Muhammad Bahauddin an-Naqsyabandi itu selalu berzikir dengan hatinya sampai terukuir dan tampak lafadz Allah SWT. Di luar hatinya, karena itulah (thariqah ini) di sebut dengan Naqsyabandiyah (Ngajuk \& Sholeh, 2012: 486).

Tarekat Naqsyabandiyah adalah satu sistem atau metode ataupun cara untuk membawa umat manusia kembali kepada Allah, sehingga mereka sampai ke hadirat Allah, yakni mengadakan kontak (hubungan) jiwa dengan Allah dan akhirnya mereka mendapat keridhaan Allah. Berkekalan berkepanjangan mengingat Allah dalam arti yang seluasluasnya adalah pokok kebahagiaan dunia dan akhirat, serta merupakan pula suatu jembatan emas untuk mencapai perdamaian dunia yang kekal abadi (Djalaluddin, 2005: 89). Sebagai jalan spiritual yang ditempuh ulma Tarekat oleh para sufi atau zahit di sepanjang zaman. Setiap orang yang menempuhnya mungkin mempunyai pengalaman yang berbeda-beda. Sekalipun tujuannya adalah sama, yaitu menuju atau mendekati Tuhan atau bersatu denganNya, baik dalam arti majasi ataupun hakiki, baik dalam apa yang disebut sebagai kesatuan mistik (Ittihad) (Kartanegara, 2006: 16).

Tarekat yang pendiriannya dinisbatkan kepada wali quthub bernama Muhammad Bahauddin bin Muhammad bin Muhammad al- Syarif Al-Husaini AlHasani Al-Uwaissi Al-Bukhari, lebih dikenal dengan sebutan Syeikh anNaqsabandi (Ngajuk \& Sholeh, 2012: 486).

Adapun manfaat-manfaat Thariqatthariqat itu (mengingat Allah diantaranya; (1) Mamfaat Ilmu Thariqat (Ilmu Ma'rifatullah) yamh kita amalkan semata-mata dengan roh saja (tanpa ada lidah) di 'almul roh yakni kaluar tidak kita terima talkin/baiat ilmu Ma'rifatullah (ilmu madani), yang diajarkan Allah berarti kita telah kafir (ingkar) di 'alamu Arwah. Bahkan roh, Iblis, roh Fir'aun dan seluruh roh-roh telah mengaku mengingat Allah dan tidak ada roh yang ingkar semasa di 'alamul Arwah. (2) Bila kita akan pindah ke dalam kandungan ibu, roh kita dalam genggaman malaikat ('alam malakut) lupa kepada Allah, maka roh itu, akan hancur hangus binasa dengan genggaman Malaikat. (3) Mamfaat Ilmu Ma'rifatullah yang ketiga, sekiranya 
roh dalam kandungan ibunya 5 bukan lagi, lupa kepada Allah, maka jasad anak (calon) manusia itu, aka gugur dalam kandungan ibunya, inilah maka ada anak yang cedera (binasa) tidak bisa lahir, ke muka bumi. (4) Untuk mendapatkan Takhalli Tahalli /Tajalli. Takhalli, Tahalli dan Tajalli ialah tiga utir perkataan itu menjadi Bungan bibir ahli Tharikat. Takhalli yaitu melepaskan diri dari perangai-perangai yang tercela, yakni membuang sifat kejahatan (mazmumah). Dengan kata lain maksud Tajalli ialah terbuka hijab dari hati kita, maka sampailah ia ke makam kasyaf. Adapun Takhalli pada permulaan (hidayah) untuk batu loceta kepada Tahalli (pertengahan). Insya Allah sampai lah ia kepada Tahalli (pertengahan). Insya Allah sampailah ia kepada tajalli inilah kesudahan ujung jalan (Musyadah). (5) Mengamalkan Tharekat Islam itu, adalah batu loncatan untuk menyapaikan ilmu tashaswwuf dan ilmu tauhid kita. Bertasawwuf adalah teori (rancangan-rancana), pada hal bertaraikat Islam itu ialah pratek (pelaksanaan perbuatan). Ber-Tharekat adalah wasilah (batu locatan) untuk memperdalam ilmu Tasawwuf dan ilmu Tauhid. (6) Sengat banyak peringatan Allah, dalam Al-Qur’an bahwa manusia itu bermusuhan (melawan) dan beradu dengan Syaitan Iblis. Iblis Syaitan bedaya upaya membinasakan semasa kita hidup, terutama sekali kita berdayakannya agar kita mati kafir, supaya kita bersma-sama dengan Iblis Syaitan itu kekel dalam neraka. (7) Kemudia manfaat ilmu Tharekat dijelaskan dalam hadis Nabi Muhammad SAW yaitu: " dalam tubuh anak adam adalah segumpal daging (hati), jika hati itu baik, maka baiklah dan tubuhnya (perbuatannya). Jika hati itu jahat, maka jahatlah perbuatannya" (Djalaluddin, 2005: 13-17).

Kemudian beberapa literatur juga telah melakukan penelitian di berbagai daerah Indonesia mengenai pendidikan Akhlak bahwasanya pentingnya ilmu tasawuf dalam mengembangkan akhlak manusia melalui ajaran Tarekat Naqsabandiyah diantaranya penelitian yang dilakukan oleh Suherman (2015) Memfokuskan pada penelitian tentang Nilai-nilai Pendidikan Akhlak dalam Ajaran Tarekat Naqsababandiyah di Persulukan. Bambussalam Langkat. Adapun perbedaan penelitian di atas dengan penelitian yang akan penulis lakukan terletak pada tempat pelaksanaanya, nama tokoh, dan upaya penyelesainya. Lebih lanjut penelitian oleh Luqman (2016) Dukuh Tompe, Kabupaten Boyolali penelitianya memfokuskan kajian teksnya yaitu pendidikan agama Islam dan perubahan perilaku sosialnya menerangkan secara perinci tentang kajian tokoh dan literatur.

Sementara penelitian yang dilakukan Kholil Supatmo (2017) Fakultas Ushuludin dan Dan Studi Agama Universitas Islam Negri Raden Intan Lampung yang berjudul Aktualisasai Ajaran Tarekat Naqsabandiyah pada Perubahan Prilaku Sosial Jamaah di Desa Sidomulyo, Kecamatan Bangun Rejo. Adapun hasil penelitianya ialah Aktualisasi ajaran Tarekat Naqsabandiyah pada perubahan tingkah laku sosial jamaah dilakukan melalui serangkaian kegiatan dzikir, wirid, do'a dan kegiatan sosial di lingkungan desa. Kemudian penelitian yang dilakukan oleh Agung Santoso (2019) Fakultas Agama Islam Universitas Islam Riau yang berjudul upaya guru dalam membina akhlak santri melalui pelaksanaan ibadah shalat di Pondok Pesantren Darusalam Saran Kabun Rokan Hulu adapun hasil penelitianya ialah upaya guru membina akhlak santri terhadap Allah ialah melalui penerapan disiplin waktu shalat, penerapan pelaksanaan ibadah shalat Sunnah seperti shalat sunah qobliah dan ba'diah dan juga penerapan budaya mengantri ketika berwudhu.

Dari berbagai penelitian terdahulu, dapat dilihat bahwa pembinaan akhlak 
terhadap masyarakat dilakukan berbagai upaya dalam membangun pendidikan ahklak masyarakat. Tarekat Naqsabandiyah melakukan upaya pembaiat masyarakat yang mau menjadi murid atau jamaah Tarekat Naqsabndiyah untuk memberikan efek kepada murid yang dibaiat sengga menyegerakan dirinya untuk bertobat. Guru (mursyid), dan wakil guru (badal/khalifah) Tarekat Naqsabandiyah telah melaksanakan pendidikan akhlak masyarakat dengan melakukan berbagai upaya seperti diatas tetapi peneliti survey belum keseluruhan masyarakat memiliki akhlak yang sesuai dengan yang diharapkan sehingga terdapat permasalahan yang berhubungan deangn akhlak masyarakat desa Ukui Dua diantaranya sebagai berikut; (1) Kurangnya rasa saling menghormati secara saksama. (2) Tidak adanya saling menghormati dalam perbedaan pendapat. (3) Rendahnya nilai akhlak yang diproleh masyarakat. (4) Kurangnya pengetahuan yang dimiliki oleh masyarakat. (5) Rendahnya keinginan masyarakat tentang ilmu Islam. (6) Kemudian selain itu permasalahan akhlak ini juga terlihat dari masih adanya yang tidak menjalankan syari'at Islam yang sesuai dengan ajaran yang telah ditetapkan.

Dari gejala-gejala di atas mengindikasihkan masih rendahnya Pendidikan akhlak masyarakat desa Ukui Dua kabupaten Pelalawan Riau. Untuk itu diperlukan upaya yang lebih dalam membangun pendidikan akhlak masyarakat desa Ukui Dua.

\section{METODE PENELITIAN}

Penelitian yang sedang peneliti lakukan ini adalah penelitian kualitatif. Hasil penelitian ini tertulis berisikan kutipan-kutipan dari data untuk mengilustrasikan dan menyediakan bukti presentasi. Data yang dikumpulkan adalah berupa transkip wawancara, catatan lapangan fotografi, videotape,
Dokumen pribadi, memo, dan rekamanrekaman resmi lainya (Heriyanto, 2018).

Dalam penelitian kualitatif ini menggunakan pendekatan lapangan. Penelitian ini bertujuan untuk mengetahui apa kontribusi Tarekat Naqsabandiyah dalam membangun Pendidikan Akhlak Masyarakat Desa Ukui Dua, Kabupaten Pelalawan Riau

Adapun yang menjadi subjek dalam penelitian ini guru (mursyid), wakil guru (badal/khalifah), tokoh masyarakat dan jamaah Tarekat Naqsabandiyah. Sedangkan yang menjadi objek penelitian ini yaitu kontribusi Tarekat Naqsabandiyah dalam membangun Pendidikan akhlak masyarakat desa Ukui Dua Kecamatan Ukui Kabupaten Pelalawan-Riau).

Populasi penelitian ini terdiri lima informan, yaitu tiga informan yang berasal dari dua orang wakil guru (badal/khalifah) dan satu tokoh masyarakat (tokoh adat) dan perangkat desa (jamaah tarekat) sebagai infoman pendukung yaitu orang-orang yang dipilih diwawancarai dan observasi sesuai tujuan riset. Penelitian ini dilakukan dengan melibatkan lima orang yang menjadi informan.

\section{HASIL DAN PEMBAHASAN}

Hasil wawancara, observasi dan dokumentasi akan menunjukkan apa Kontribusi Tarekat Naqsabandiyah dalam membangun pendidikan Akhlak di Desa Ukui Dua Kabupaten Pelalawan Riau. Wawancara ini ditujukan kepada lima informan yaitu H.Atan K, Muhammad Isyah, Kadir B, Ali Amran s, H.M.Yusuf. Kemudian data yang diperoleh akan disajikan dalam bentuk uraian singkat sesuai dengan konsep operasional secara kualitatif. Adapun penyajian dari hasil wawancara dan observasi tentang pelaksanaan Apa Kontribusi Tarekat Naqsabandiyah dalam membangun pendidikan Akhlak di Desa Ukui Dua Kabupaten Pelalawan Riau, dengan tiga 
orang informan, dua orang informan pendukung

Berdasarkan hasil wawancara dengan jamaah tarekat naqsabandiyah desa Ukui Dua adalah:

\section{Kontribusi Tharekat Naqsabandiyah terhadap Akhlak masyarakat kepada Allah}

Informan I : H.M. Yusuf

Masyarakat Ukui Dua merupakan masyarakat asli tempatan yang sering dan akrab bersama alam. Oleh karenanya masyarakat Ukui Dua tidak heran jika banyak kepercayaan yang dibangun masih menggunakan kepercayaan animism dan dinamisme. Seiring kemajuan zaman dan masuknya para guru Mursyid membawa sentuhan nilainilai keIslaman, maka secara beransur kebiasaan dan cara pandang masyarakat mulai mengalami perubahan termasuk dalam perihal akhlak terhadap Allah Swt. Hal tersebut masyarakat dapatkan melalui kajian-kajian ilmu agama melalui dakwah-dakwah oleh Syek Mursyid. Oleh karenanya ajaran Tarekat Naqsabandiyah di desa Ukui Dua terutama megenai rasa Taqwa Kepada Allah dan berbaik sangka terhadap qodho dan qodarnya Allah Swt. Yaitu memelihara diri dari siksaan Allah dengan mengikuti segala perintah-Nya dan menjauhi segala larangan-Nya. Oleh karenanya pula, buah ataupun hasil dari kajian-kajian dari Tarekat Naqsabandiyah di Ukui Dua mampu menghadirkan rasa Iman dan Taqwa kepadaAllah Swt. Sehingga mereka merasa selalu diawasi dan berada dalam genggaman Allah Swt. Maka hasil selanjutnya seseorang itu akan mampu memelihara dirinya dari segala sesuatu yang mengundang kemurkahan Allah Swt dan dari segala sesuatu yang mendatangkan kemudharatan, baik bagi dirinya pribadi maupun orang lain. Informan II : Muhammad Isyah

$$
\text { Dengan adanya Tharekat }
$$

Naqsabandiyah maka muncullah kegiatan kegiatan ceramah agama, Tabligh Akbar dan kajian-kajian keIslaman lainya bahwa segala sesuatu yang kita perbuat akan mendapatkan balasan dari Allah swt. Bersyukur atas nikmat Allah berikan kepada kita agar kita ikhlas dalam menjalani hidup yang penuh cobaan dan ujian segalah sesuatu datang dari Allah kembali kepada Allah.

Informan III: H.Atan K

Adapun kontribusi Tharekat Naqsabandiyah kepada masyarakat terhadap akhlak kepada Allah ialah dengan ajaran Tharekat masyarakat mengetahui artinya Tawakkal. Karena di dalam tarekat kita mengetahui setiap orang yang beriman bahwa semua urusan kehidupan semua ada di tangan Allah. maka dengan ini kita tidak akan pernah tidak merasa bersyukur atas apa yang terjadi dalam kehidupan.

\section{Kontribusi Tharekat Naqsabandiyah kepada masyarakat dalam beribadah kepada Allah.}

Informan I : H.M. Yusuf

Masyarakat banyak mengetahui tentang amalan-amalan yang harus dilakukan setelah shalat seperti halnya berdzikir kepada Allah. Dzikir ini bisa dilakukan dengan dua cara bisa menggunakan lisan (jahr) atau dengan sir (qolbi) sebelum lanjut zikir ada beberapa hal yang harus di tobatkan oleh anggota lahir yang berjumlah 8 macam yaitu dosa mata, dosa telinga, dosa hidung, dosa mulut, dosa perut, dosa tangan, dosa kaki, dosa qubul/kemluan dan dubur,. Ada suatu firman Allah yaitu Aku tidak menciptakan jin dan manusia melainkan agar mereka beribadah kepada- $\mathrm{Ku}$,( $\mathrm{Az}$ Zariat,56). Menuntut ilmu agama dan berbakti kepada kedua orang tua kita dan mengesankan segala bentuk ibadahtan bagi Allah seperti berdoa, meminta (hajat), tawakal bahkan berharap.

Informan II : Muhammad Isyah

Yasinan. Yasinan adalah pengajian membaca Surat Yasin secara berjama'ah dan dilanjutkan dengan Tahlil. Tujuan dari yasinan adalah untuk mendoakan sanak saudara yang sudah meninggal, 
meminta do'a keselamatan terhadap apa yang kita lakukan. Mereka percaya dengan membaca surat yasin dan kalimayun thoyyibah (kalimah yang baik), maka sanak saudara yang sudah meninggal akan diampuni dosa-dosanya oleh Allah. Pembacaan surat yasin ini dilakukan 7 hari berturut-turut oleh masyarakat kerumah orang yang meninggal. Biasanya sebelum pembacaan yasin ini dimulai oleh Ustadz. Tausiyah menyampaikan apa yang perlu disampaikan oleh Ustadz dan dilanjutkan ahlil bait (keluarga) kepada jama'ah.

Informan III : H.Atan K

Kontribusi Tharekat Naqsabandiyah dalam ibadah adalah puasa pada bulan rajab 10 hari penuh atau lebih bulan ini adalah bulan kemulian keutamaanya yaitu umat Islam akan mendapatkan ladang pahalanya, dan pada bulan sya'ban yaitu bulan yang dinaikkannya berbagai amalan kepada Allah sehingga ada baiknya masyarakat melakukan amalanamalan yang dapat menambah pahala, misalnya dengan puasa dengan niat mendekatkan diri kepada Allah dalam hal beribadah maka masyarakat akan lebih giat, tekun dan khusyu'. Ia tidak akan melalaikan lagi kewajibanya terhadap Allah SWT.

\section{Kontribusi Tharekat Naqsabandiyah kepada masyarakat terhadap keyakinan kepada Allah}

Informan I : H.M. Yusuf

Karena adanya penciptaan dan penguasaan alam semesta dideskripsikan sebagai suatu tindakan kemurahan hati yang paling utama untuk semua ciptaan yang memuji keagungan-Nya dan menjadi saksi atas keesanya dan kuasa-Nya. Sifat mausia yaitu hina, papo (tidak ada kemampuan), dhoif (lemah tidak ada kekuatan), lemah (tidak ada daya dan upaya), sifat Allah yaitu kuat, kuasa, kaya, dan mulia. Sehingga sepenuhnya aqidah tauhid hanya disnadarkan kepada Allah Swt. Bila tauhid disandarkan kepada selain Allah SWT, maka itu syirik.
Informan II : Muhammad Isyah

Kita menyakini adanya Allah, rezeki, maut dan jodoh ada ditangan Allah. Maka dari itu kita tidak boleh memiliki sifat syiri'k atau menduakan Allah kita tidak boleh menyembah selain Allah seperti percaya terhadap dinamisme dan animisme yang mana dahulunya banyaknya kepercayaan orang-orang kampung pada kekuatan gaib yang misterius agar apa yang dinginkannya terkabulkan, di tambah lagi kepercayaan terhadap benda-benda yang dianggap sakral. Oleh sebab itu kemurnian dari tauhid menjadi muaranya.

Informan III: H.Atan K

Kita melakukan syariat Islam tetapi tidak disertai dengan keyakinan mereka merupakan orang-orang yang kufur. Kemudian orang yang menyatakan imannya sungguh-sungguh maka dipastikan dalam hatinya, dan dibuktikan dengan amal perbuatannya itulah yang disebut dengan orang yang yang menyakini dengan akidah yang lurus. Orang yang beriman atau berakidah Islam, akan tetapi tidak melaksanakan syari'at mereka ialah orang-orang yang munafik. Karena apa yang kita kerjakan ialah sesuatu yang pantas atau tidak. Yang tidak pantas demi kekukuhan akidah harus kita tingalkan dan yang semestinya kita kerjakan sekalipun berat, kalau itu tuntutan syari'at harus kita laksanakan itulah hal yang harus kita lakukan dalam keyakinah akidah terutama dalam beribadah. Sehingga kemurnian terhadap akidah yang lurus juga menjadi misi akhirnya

\section{Kontribusi Tarekat Naqsabandiyah terhadap Akhlak masyarakat kepada Rasul}

Informan I: H.M. Yusuf

Ridha beriman kepada rasul yang artinya kita iklas mengikuti ajaran-ajaran yang dibawa para ulama sebagimana yang dismpaikan bahwa ulama adalah pewaris para nabi dengan kutipan ulama yang tidak menyalahi qur'an dan hadis, 
memuliakan Rasul Saw dan menjunjung tinggi ajaran-ajaran yang dibawanya agar kita dapat menjadi pedoman semasa kita hidup di dunia dan di akhirat kelak dan kita mengetahui bahwasanya rasul adalah panutan suri tauladan yang harus kita contoh. Kemudian hadist dan As-sunnah merupakan pegangan yang kuat setelah Al-qur'an yang mesti dipegang teguh dalam keyakinan masyarakat (dalam melakukan sesuatu).

Informan II: Muhammad Isyah

Masyarakat mengetahui tentang pentingnya memperingati hari-hari besar Islam seperti memperingati maulid Nabi Muhammad Saw. dan isra' mi'raj yang dilaksanakan di Masjid, Musholla, maupun tempat-tempat lainnya secara berjama'ah. Didalam pembahasan maulid Nabi Saw yaitu mengisahkan masa hidupnya Rasul Saw. sejak dari kecil sampai dewasa. Didalamnya tentu banyak hikmah yang dapat dipetik. Selanjutnya dalam kisah isra' wal mi'raj Nabi Muhammad Saw mampu menghadirkan rasa iman dan keyakinan yang begitu kokoh terhadap Rasul Saw dalam kehidupan masyakarat.

Informan II: H.Atan K

Kita juga seharusnya mencintai orang-orang yang dicintai beliau dan membenci orang-orang yang dibencinya, lebih khusus mencintai dan memuliakan keluarga dan sahabat-sahabat beliau dengan mengucapkan shalawat atas nabi dengan bacaan Allahumma solli ala saiyyidina Muhammad wa'alaalihi saiyyidina Muhammad.

\section{Kontribusi Tharekat Naqsabandiyah dalam hubungan baik dengan masyarakat}

Informan I: H.M. Yusuf

Selain kita dituntut adanya hubungan baik dengan Allah dan alam semesta kita juga harus menjalin hubungan baik dengan sesama manusia. Yaitu seperti hal yang kecil ketika bertemu kita mengucapkan salam dan menjawab salam ketika bertemu dengan saudara kita di jalan. Apabila orang memberikan salam maka kita wajib menjawab salam saling menghormati maka kita harus membalas dengan penghormatan dengan yang lebih baik atau kita harus membalas dengan hal yang serupa. Hal ini bukan terbatas kepada saudara kita yang seiman dan seakidah saja akan tetapi saudara kita non muslim kita juga harus bertoleransi dalam beragama.

Informan II: Muhammad Isyah

Salah satu kontribusinya terhadap masyarakat ialah adanya rasa kepedulian dalam mejenguk orang sakit. Dengan meluangkan waktu untuk menjenguk saudara kita yang sakit dia merasa senang karena masih ada saudaranya yang peduli terhadap dirinya. Ini adalah salah satu bentuk kontribusi Tharekat Naqsabandiyah dalam menjalin hubungan baik sesama masyarakat. Kemudian ketika mau manyabut bulan ramahdhan biasanya masyarakat Ukui Dua berziarah kemakam sanak saudarahnya bergotong royong membersikan kuburan disekitarnya. Hal ini juga dilakukan dalam bergotong royong dalam membersikan masjid dalam menyabut bulan suci ramadhan.

Informan III : H.Atan K

Salah satu kontribusinya terhadap masyarakat ialah memenuhi undangan suadara kita seperti kenduri, mendoa, dan halal bihalal lainnya. Hal yang lain kontribusi tarekat ialah apabilah ada orang meninggal dunia, maka masyrakat secara kifayah wajib memandikan, mengapani, mensholatkan dan menguburkannya.

\section{Kontribusi Tharekat Nasabandiyah terhadap Akhlak masyarakat kepada alam semesta}

Alam merupakan hal yang tidak bisa dipisahkan dari kebiasaan dan pekerjaan masyakarat Ukui Dua pada awal mulanya, oleh karenanya masyaraka Ukui Dua merupakan masyarakat yang sebelumnya juga telah mengenal berbagai cara untuk 
menghormati alam termasuk Ketika kedatangan Tharekat Naqsabandiyah maka masyarakat semakin sadar akan memelihara dan melestarikan alam dan seisinya. Hal ini bisa dilihat dari beberapa jawaban dari pertanyaan-pertanyaan berikut ini:

\section{Kontribusi Tharekat Naqsabandiyah dalam mencintai hewan dan tumbuhan} Informan I: H.M. Yusuf

Kontribusi Tharekat Naqsabandiyah salah satunya dalam mencintai hewan, yaitu kita tidak boleh, menganiaya, membunuh apalagi mengurung hewan tersebut tidak memberikan makan dan minum sehingga mati karena setiap makhluk di muka bumi ini dia berdzikir kepada Allah Swt. Sedangkan dalam memelihara tumbuhan kita tidak boleh merusak tumbuh-tumbuhan karena dia juga merasakan sakit seperti makhluk yang bernyawa lainya. Dengan adanya Tarekat kita mengetahui bagaiamana memelihara hewan dan tumbuhan sehingga kita bisa menjalin hubungan baik dengan alam semesta.

Informan II: Muhammad Isyah

Yaitu salah satunya memberikan perlindungan terhadap tumbuhan dan hewan mengangkat kisah dari cerita Nabi Sulaiman. Bahwasanya ketika Nabi Sulaiman jadi raja dia mempu mersakan adanya makhluk Allah yang kecil pun berhak untuk dilindungi seperti semut, begitu juga seharusnya manusia terhadap makhluk-makhluk Allah yang kecil dan tidak terlihat oleh kasat mata.

Informan III: H.Atan K

Manusia ialah seorang Khalifah di muka bumi ini, maka dari adanya ajaran Tharekat Naqsabandiyah maka masayarkat mengetahui bahwa kita sebagai manusia berhak menjaga dan memliha lingkungan dan alam semesta. Berdasarkan teknik analisis data yang penulis lakukan adalah sebagai berikut: Mengumpulkan data melalui wawancara, observasi, dan dokumentasi, mereduksi data, menyeleksi data yang diperoleh dari hasil wawancara, observasi dan dokumentasi data dalam bentuk uraian singkat yang diperoleh dari 3 informan dari sebagai khalifah, pengikut Tarekat dan sebagi tokoh masyarakat (ninik mamak) dan dua orang pendukung masyarakat dan kepala dusun dan kesimplan data yang diperoleh. Adapun analisis dari wawancara observasi dan dokumentasi kepada informan dan di dukung oleh penjelasan informan pendukung untuk mendapatkan informasi tentang kontribusi/sumbangan Tharekat Naqsabandiyah dalam membangun Pendidikan Akhlak di desa Ukui Dua. Untuk lebih jelasnya ada 20 poin sumbangan tarekat naqsbandiyah dalam pendidikan akhlak, yaitu:

Pertama, Menghadirkan rasa Iman dan Taqwa kepada Allah Swt. Menghadirkan rasa Iman dan Taqwa kepadaAllah Swt. Sehingga dapat meningkatkan keyakina kepada Allah dan merasa bahwa hidup ini sangat berarti, disetiap tindakan dan perbuatan akan terasa diawasi sang pencipta yaitu Allah.

Kedua, Memelihara dirinya yaitu menjaga merawat dari segala sesuatu keburukkan hati yang mati sehingga mengundang kemurkahan Allah Swt. dan dari segala sesuatu yang mendatangkan kemudharatan, baik bagi dirinya pribadi maupun orang lain.

Ketiga, Ceramah agama dan Tabligh Akbar yaitu memperdalam ilmu dan memberikan penjelasan tentang arti dari kehidupan yang sebenarnya sehingga jamaah tarekat taat dan tau batasanbatasan dalam kehidupan.

Keempat, Kajian-kajian keIslaman yaitu memperjelas amalan-amalan tarekat Naqsabandiyah yang mendekatkan diri kepada kepada Allah. hal-hal apa saja yang harus diperbuat didalam keseharian atau amalan-amanlan pada setiap waktunya agar menujukan ketaatan masyarakat terhadap pencipta yaitu Allah. 
Kelima, Tawakkal dan Bersyukur yaitu menunjukan bahwa nikmat Allah berikan kepada kita agar kita ikhlas dalam menjalani hidup yang penuh cobaan dan ujian segalah sesuatu datang dari Allah akan kembali kepada Allah. dengan berserah diri sepenuhnya kepada Allah akan timbul rasa nikmatnya hidup yang sebenarnya.

Keenam, Tobat dan Dzikir yaitu kembali mengingat kesalah anggota tubu yang lahir maupun yang batin tidak akan mengulangai kesahan itu lagi, kesalahan oleh anggota lahir yang berjumlah 8 macam yaitu dosa mata, dosa telinga, dosa hidung, dosa mulut, dosa perut, dosa tangan, dosa kaki, dosa qubul/kemluan dan dubur. Yang batin yaitu 7 macam yaitu Lathifatul Qolbi, Lathifatur Ruh, Lathifatus Sirri, Lathiftul Khafiy, Lathifatul Akhfa, Lathifatun Nafsi anNathiqah, lathifatul Jami'ul Badan. Sehingga sucilah anggota tubuh dan diamalkan setiap selesai shalat. Setelah suci tubuh dilanjutkan dengan Dzikir mengingat Allah dalam setiap detiknya dan zikir terbagi menjadi dua cara bisa menggunakan lisan (jahr) atau dengan sir (qolbi). Berzikir adapat menibulkan rasa cinta terhadap sang pencipta yaitu Allah.

Ketujuh, Yasinan yaitu pengajian membaca Surat Yasin secara berjama'ah dan dilanjutkan dengan Tahlil. Tujuan dari yasinan adalah untuk mendoakan sanak saudara yang sudah meninggal, meminta do'a keselamatan terhadap apa yang kita lakukan. Mereka percaya dengan membaca surat yasin dan kalimayun thoyyibah (kalimah yang baik), maka sanak saudara yang sudah meninggal akan diampuni dosa-dosanya oleh Allah. Pembacaan surat yasin ini dilakukan 7 hari berturut-turut oleh masyarakat kerumah orang yang meninggal. Biasanya sebelum pembacan yasin ini dipandu oleh Ustadz.

Kedelapan, Tausiyah dan puasa. Tausiyah menyampaikan ajaran-ajaran dan ajakan kepada masyarakat untuk mendekatkan diri kepada Allah melalui ibadah-ibadah wajib maupun ibadah Sunnah lainyan. Puasa adalah amalan yang harus dipenuhi pada setiap bulan rajab 10 hari penuh atau lebih bulan ini adalah bulan kemulian keutamaanya yaitu umat Islam akan mendapatkan pahala sebesar/seluas ladang pahalanya, dan pada bulan sya`ban yaitu bulan yang dinaikkannya berbagai amalan kepada Allah. sehingga ada beberapa masyarakat melakukan amalan-amalan yang dapat menambah pahala kebaikan, dan dapat mendekatkan diri kepada Allah.

Kesembilan, Tauhid yaitu keesanya dan kuasa-Nya ini membuktikan akhlak kepada Allah. Karena adanya penciptaan dan penguasaan alam semesta dideskripsikan sebagai suatu tindakan kemurahan hati yang paling utama untuk semua ciptaan yang memuji keagunganNya dan menjadi Sifat mausia yaitu hina, papo (tidak ada kemampuan), dhoif (lemah tidak ada kekuatan), lemah (tidak ada daya dan upaya), sifat Allah yaitu kuat, kuasa, kaya, dan mulia. Sehingga sepenuhnya aqidah tauhid hanya disandarkan kepada Allah Swt. Dan menghilangkan sifat syiri'k yang sebagain masyarakat percaya kepada dinamisme dan animism, dahulunya banyaknya kepercayaan orang-orang kampung pada kekuatan gaib yang misterius agar apa yang dinginkannya terkabulkan, di tambah lagi kepercayaan terhadap bendabenda yang dianggap sakral. hilangnya sifat syiri'k maka timbullah kemurnian tauhid itu sendiri.

Kesepuluh, Ridha beriman kepada rasul artinya kita ikhlas mengikuti ajaranajaran yang dibawa para ulama sebagimana ulama pewaris dari para nabi dengan kutipan ulama yang berpegang teguh pada qur'an dan hadis, dan memuliakan Rasul Saw serta menjunjung tinggi ajaran-ajaran yang dibawanya agar kita dapat menjadikan pedoman semasa kita hidup di dunia yang fana dan sampai ke kehidupan abadi yaitu akhirat. 
Kesebelas, Maulid Nabi Muhammad Saw. dan isra' mi'raj yaitu mengakat kisah Rasullah agar dapat menjadi panutan suri tauladan yang harus kita contoh perbuatan-perbutannya agar kita terapkan dalam kehidupan bermasyarakat dan demikian timbulah rasa cinta kepada Rasululluh.

Kedubelas, Hadist dan As-sunnah merupakan pegangan yang kuat setelah Al-qur'an yang mesti dipegang teguh dalam keyakinan kita beragama (dalam melakukan sesuatu), menjalankan sunahsunah melebihi ibadah-ibadah wajib tampah meninggalkan ibadah yang wajib.

Ketigabelas, Bershalawat atas Nabi dengan bacaan Allahumma solli ala saiyyidina Muhammad wa'alaalihi saiyyidina Muhammad, agar kelak dapat safatnya, dan mencintai dan memuliakan keluarga dan sahabat-sahabat beliau SAW. Agar kita tergolong orang taat kepada rasulullah adalah orang yang berjanji setia kepada Allah.

Keempatbelas,

Mengucapkan salamyaitu hubungan sesama manusia memberikan salam maka kita wajib menjawab salam dan saling menghormati dalam perbedaan dan tidak menjatukahkan mertabat orang lain.

Kelimabelas, Bertoleransi dalam beragama hal ini bukan terbatas kepada saudara kita yang seiman dan seakidah saja akan tetapi saudara kita non muslim kita juga harus mengharaga satu sama lain.

Keenambelas, Rasa kepedulian terhadap orang yang kurang mampuh (lemah) atau orang yang sedang sakit. Dengan meluangkan waktu untuk menjenguk saudara kita yang sakit maka tibullah rasah kepedulian dan persaudaraan yang baik, maka akan muncul rasa senang dihati orang yang sedang sakit karena masih ada saudarasaudaranya yang peduli terhadap dirinya.

Ketujuhbelas, Berziarah kemakam sanak saudarahnya bergotong royong membersikan kuburan disekitarnya. Hal ini menunjukan bahwa bergotoroyong dapat mempererat silaturahmi dalam kebaikan seperti membersikan masjid, menyabut bulan suci Ramadhan.

Kedelapanbelas,

Memenuhi undangan suadara kita seperti kenduri, mendoa, dan halal bihalal lainnya. Hal ini menujukan kepedulian kekeluargan sesame masyarakat setempat, jamaah Tarekat Naqsabandiyah selalu ikut serta dalam mengembang pembinaan kebiasaan dalam hubungan Ukhuwah Islamiyah. Hak ini dilihat ketika adanya masyarakat yang mengangalami musibah seperti meninggal dunia, maka ulama dan masyarakat secara kifayah wajib memandikan, mengapani, mensholatkan dan menguburkannya.

Kesembilanbelas, Mencintai hewan dan Memelihara tumbuhan yaitu merupakan akhlak manusia terhadap alam semesta seperti agar terciptanya kelestarian hawan flora dan fauna sehingga terjadi keseimbangan antara alam dan manusia, Islam melarang adanya penganiaya, membunuh, menangkap dan mengurung hewan tersebut dan pada akhinya tersiksa dan mati. Hal ini dilarang keras oleh agama dan pemerintahan Indonesia karena akan menimbulkan kerusakan

Keduapuluh, Khalifah adalah manusia sebagai pemimpin di muka bumi ini, maka dari kita harus sadar bahwa menjaga dan memliha lingkungan dan alam semesta ini yaitu manusia yang beriman dan bertaqwa kepada sang pencipta yaitu Allah swt.

Dari penjelasan oleh 3 informan sesuai dengan wawancara tersebut ada 4 kegiatan dimasyarakat dalam membangun pendidikan Akhlak. Namun, setelah diobservasi yang lihat ada 2 lagi dari pendudukung yang tidak disebutkan dalam wawacara, yaitu: kenduri dan halal bihalal karena sudah menjadi adat kebiasaan masyrakat di Desa Ukui Dua, agar terjalin tali silatuhrahim dengan sesama manusia itu dengan baik. 


\section{PENUTUP}

Berdasarkan hasil temuan dan analisa uraian pada pada penelitian ini dapat disimpulkan bahwa kontribusi Tharekat Naqsabandiyah dalam membangun Pendidikan Akhlak di Desa Ukui Dua ialah sebagai berikut: Menghadirkan rasa Iman dan Taqwa kepada Allah SWT. Memelihara dirinya; Ceramah agama dan Tabligh Akbar; Kajian-kajian keIslaman; Tawakkal dan Bersyukur; Tobat dan Dzikir; Yasinan; Tausiyah dan puasa; Tauhid; Ridha; Maulid Nabi Muhammad Saw. dan isra' mi'raj; Hadist dan As-sunnah; Bershalawat; Mengucapkan salam; Bertoleransi; Rasa kepedulian; Berziarah; Memenuhi undangan; Mencintai hewan dan Memelihara tumbuhan; Khalifah.[]

\section{DAFTAR RUJUKAN}

Abdullah, Luqman. "Kontribusi Tarekat Naqsabandiyah

Terhadap Pendidikan Agama Islam Dan Perubahan Perilaku Sosial Jamaah (Studi Kasus Jamaah Tarekat Naqsabandiyah Di Dukuh Tompe, Kabupaten Boyolali)." Nazhruna: Jurnal Pendidikan Islam 1.1 (2018): 1-19.

Agus, Zulkifli. "Pendidikan Islam Dalam Perspektif Al-ghazali." Raudhah Proud To Be Professionals: Jurnal Tarbiyah Islamiyah 3.2 (2018): 2138.

Anwar, Saepul. Peranan Bimbingan Tarekat Tijaniyah dalam Membangun Kecerdasan Emosional dan Spiritual Ikhwannya (Penelitian pada Komunitas Tarekat Tijaniyah di Zawiyah Tarekat Tijaniyah Kecamatan Samarang Kabupaten Garut). Diss. UIN Sunan Gunung Djati Bandung, 2014.

Djalaluddin. Sinar Keemasan Pembelajaran Tharekat Shufiah Naqsyabandiyah jilid 1. Surabaya: Terbit Terang, 2005.
Heriyanto, Heriyanto. "Thematic Analysis sebagai Metode Menganalisa Data untuk Penelitian Kualitatif." Anuva: Jurnal Kajian Budaya, Perpustakaan, dan Informasi 2.3 (2018): 317-324.

Luqman, A. Kontribusi Tarekat Naqsyabandiyah Terhadap Pendidikan Agama Islam dan Perubahan Perilaku Sosial, Skripsi, Fakultas Ilmu Terbiyah dan Keguruan Universitas Islam Negeri Sunan Kalijaga Yogyakarta, 2016.

Mubarok, Muhammad Rois, and Giyoto Giyoto. Pendidikan Akhlak Tasawuf Dalam Perang Uhud (Studi Analisis Buku Sirah Nabawiyah Karya Syaikh Shafiyyurrahman Al-Mubarakfuri. Diss. IAIN Surakarta, 2020.

Mulyadhi, K. Menyelami Lubuk Tasawuf. Jakarta, Penerbit Erlangga, 2006.

Nasution, S. Islam rasional. Ijtimaiyah Jurnal Ilmu Sosial dan Budaya, 3.1 (2019).

Ngajuk, Munawir Kertosono \& Sholeh Bahruddin Sengonagung Purwosari. Sabilus Salikin Jalan Para Salik Ensiklopedi Thariqah/Tashawwuf, Pondok Pesentren Ngalah, Sengonagung, 2012.

Santoso, Agung. Upaya Guru Dalam Membina Akhlak Santri Melalui Pelaksanaan Ibadah Sholat di Pondok Pesantren Darussalam Saran Kabun Rokan Hulu. Diss. Universitas Islam Riau, 2019.

Suherman, Suherman. "Nilai-Nilai Pendidikan Akhlak Dalam Ajaran Tarikat Naqsyabandiyah di Persulukan Babussalam Langkat." Journal Analytica Islamica 4.2 (2015): 351-376.

Supatmo, M. Kholil. Aktualisasi Ajaran Tarekat Naqsyabandiyah Pada Perubahan Perilaku Sosial (Studi Kasus Jamaah di Desa Sidomulyo, Kecamatan Bangunrejo, Kabupaten Lampung Tengah). Diss. UIN Raden Intan Lampung, 2017. 
Tambak, Syahraini, et al. "Internalization of Riau Malay Culture in Developing the Morals of Madrasah Ibtidaiyah Students." Al Ibtida: Jurnal Pendidikan Guru MI 7.1 (2020): 6984.

Wahyuningsih, Sri. Dinamika Suluk Dalam Tarekat Naqsabandiyyah Desa Pantai Cermin Kecamatan Tapung Kabupaten Kampar. Diss. Universitas Islam Negeri Sultan Syarif Kasim Riau, 2014. 